\title{
Effects of Beta-Adrenergic Receptor Blockade in Normal Subjects before, during, and after Triiodothyronine- induced Hypermetabolism*
}

\author{
William R. Wilson, † Ernest O. Theilen, John H. Hege, and \\ Mucio R. Valenca \\ (From the Section of Clinical Pharmacology and the Cardiovascular Research Laboratories, \\ Departments of Internal Medicine and Pharmacology, University of Iowa, \\ Iowa City, Iowa)
}

Adequate oral or intravenous doses of a betaadrenergic receptor-blocking drug, nethalide, ${ }^{1}$ produce no significant changes in the resting oxygen consumption, heart rate, cardiac output, and systemic mean arterial or mean right atrial pressures of patients with spontaneous hyperthyroidism (1). These findings do not support the concept that the hemodynamic changes in hyperthyroidism are mediated through adrenergic stimulation of betaadrenergic receptors. The work of Brewster, Isaacs, Osgood, and King, however, supported the hypothesis that the sympathetic nervous system may be responsible for the metabolic and hemodynamic changes associated with the hypermetabolic state, since the alterations induced by thyroid feeding to dogs could be abolished by epidural blockade (2). The possibility exists that spontaneous hyperthyroidism and drug-induced hypermetabolism may have similar hemodynamic findings but different mechanisms. This study was designed to test the effects of beta-adrenergic blockade in normal subjects before, during, and after the induction of hypermetabolism with triio-

\footnotetext{
* Submitted for publication January 5, 1966; accepted March 24, 1966.

This study was presented in part at the Annual Meeting of the Midwestern Section of the American Federation for Clinical Research, Chicago, Ill., November 5, 1964 (Clin. Res. 1964, 12, 340). It was supported by grants from the Iowa Heart Association, the National Heart Institute (U. S. Public Health Service grant 5TI-HE5577-03), and by Public Health Service research grant M01-FR59 from the General Clinical Research Centers Branch, National Institutes of Health.

$\dagger$ Address requests for reprints to Dr. William $R$. Wilson, Dept. of Internal Medicine, The University of Iowa, Iowa City, Iowa 52241.

12-Isopropylamino-1-[2-naphthyl] ethanol hydrochloride.
}

dothyronine. $^{2}$ We also wished to test the hypothesis that triiodothyronine augments the hemodynamic responses to graded doses of isoproterenol.

\section{Methods}

The subjects in this study were eight volunteers from the Iowa State Penitentiary, Fort Madison, Iowa. We obtained informed consent from each subject. The men were hospitalized in the General Clinical Research Center, University Hospitals, Iowa City. They ranged in age from 30 to 40 years (mean, 35 years) and in body surface area from 1.76 to $2.14 \mathrm{~m}^{2}$ (mean, 1.94). None had thyroid or cardiac disease. Each subject had a normal serum protein-bound iodine and 4- and 24-hour uptake of radioactive iodine by the thyroid gland. No subject had received antithyroid drugs. Each subject received a high caloric diet ranging from 3,500 to 5,000 calories throughout the study.

Hemodynamic responses to beta-adrenergic receptor stimulation by isoproterenol hydrochloride were recorded in the men before and after propranolol ${ }^{3}(0.15 \mathrm{mg}$ per $\mathrm{kg}$ iv) (3). Heart rate, cardiac output, and systemic arterial and mean right atrial pressures were recorded before and during the fourth minute of infusion of isoproterenol at three dose levels, before and after propranolol. Isoproterenol was given at rates of $0.025,0.05$, and 0.1 $\mu \mathrm{g}$ per $\mathrm{kg}$ per minute by a constant speed infusion pump. An adequate amount of time (10 minutes) was allowed between the infusions of isoproterenol to allow the heart rate, pressures, and cardiac output to return to control levels.

The effect of amyl nitrite on systemic mean arterial pressure, heart rate, and cardiac output was measured in these subjects before and after propranolol. This drug was given as an indirect method of testing the ability of propranolol to block reflex stimulation of beta-adrenergic receptors. The ampule of amyl nitrite was crushed and held close to the subject's nostrils during three to six breaths.

Measurements of oxygen consumption, heart rate, pres-

2 Sodium L-triiodothyronine.

3 1-(isopropylamino)-3-(1-naphthyloxy)-2-propanol hydrochloride. 
sures, and cardiac output were made also in each of the eight subjects before and during the fifth minute of exercise (bicycle ergometer) in the supine position before and after the beta-adrenergic-blocking drug. The speed of the ergometer and the work load were kept constant in each subject during each period of exercise. The order of administration of drugs (isoproterenol, amyl nitrite) and exercise was random before and after propranolol. The sequence of the three doses of isoproterenol was $0.025,0.05$, and $0.1 \mu \mathrm{g}$ per $\mathrm{kg}$ per minute. Ten to $15 \mathrm{~min}$ utes was allowed after each procedure to enable heart rates, pressures, and cardiac output to return to control levels.

These studies were done in each subject on three separate occasions. The first session was a pretreatment control (A). The second session (B) followed 14 days of treatment with triiodothyronine, 250 to $500 \mu \mathrm{g}$ per day; the third session (C) was a post-treatment control and took place 21 days after triiodothyronine had been discontinued. Body weight and radial pulse rates during sleep were measured daily. The average weight and the average sleeping pulse rate for the last 3 days of each session, oxygen consumption, serum cholesterol, and clinical evaluation were used as indexes of the subject's metabolic state. Blood was obtained each week for determination of hematocrit, leukocyte and differential cell counts, serum glutamic-oxaloacetic transaminase, and urea nitrogen. Urinalyses were also done each week.

Each patient was in a fasting state on the day of study ; no sedative was given. Measurements were made with the patient in the supine position. A small catheter was introduced through the basilic vein and advanced until its tip was lying free in the right atrium. A Cournand needle was placed in a brachial artery. Pressures were recorded from the right atrium and brachial artery with Statham strain gauges. Mean pressures were recorded by electrical integration. Pressure recordings were made immediately before cardiac output determinations. The catheter in the right atrium was filled with indocyanine green dye and connected through a three-way stopcock to a dye reservoir and injection system. The needle in the brachial artery was connected through a short polyethylene tube to the cuvette of a Gilford densitometer. Each dye injection contained $2.8 \mathrm{mg}$ of dye. Dye was injected into the right atrium, and dye curves were obtained by drawing arterial blood through the densitometer with a constant speed pump at the rate of $38 \mathrm{ml}$ per minute. Three-point calibration curves were made in each study. Cardiac output was calculated by the StewartHamilton method. Total peripheral resistance was calculated in terms of dynes $\cdot$ second $\cdot \mathrm{cm}^{-5}$. Lead I of an electrocardiogram was recorded during each cardiac output determination to measure heart rate. Dye curves, heart rates, and blood pressures were recorded with a Sanborn direct-writing oscillograph. Duplicate measurements of output and pressures were made during the initial control period before propranolol. Expired air was collected in a Tissot spirometer for 3 minutes for determination of oxygen consumption. Two measurements were made initially during the control period.
Oxygen consumption was measured again just before and during the third through the fifth minutes of exercise, before and after propranolol. All values for oxygen consumption are given in terms of standard conditions $\left(0^{\circ} \mathrm{C}\right.$ and $760 \mathrm{~mm} \mathrm{Hg}$, dry $)$.

The results obtained in the second session (during triiodothyronine administration) were compared to those of the two control sessions. Dose-response regressions were computed for the changes in heart rate, cardiac index, systemic mean arterial and mean right atrial pressures, and total peripheral resistance produced by the three doses of isoproterenol before and after propranolol (4). The control values and responses to isoproterenol in each session before and after propranolol were compared initially by analyses of variance (4). The results obtained in the hypermetabolic session before and after beta-adrenergic receptor blockade were contrasted with those of the control sessions using orthogonal contrasts (5). Control values and responses to amyl nitrite and to exercise in the three sessions were compared by analyses of variance. Student's $t$ test for paired data was used for analysis of the responses to amyl nitrite and to exercise within each session (4). Dunnett's test for multiple comparisons with a control was used to compare the effects of propranolol on the control hemodynamic values at 15,45 , and 70 minutes after the drug to the control values just before the beta-adrenergic blocking drug was given within each session $(6,7)$. F values or $t$ values derived from the analyses were considered statistically significant if $\mathrm{p}<0.05$.

\section{Results}

General. The effects of graded doses of triiodothyronine on the average sleeping pulse, oxygen consumption, body weight, and serum cholesterol of the eight normal subjects are shown in Figure 1. Triiodothyronine increased the average sleeping pulse rate from 66 to 96 beats per minute $(\mathrm{p}<0.01)$, and the resting oxygen consumption from 130 to $190 \mathrm{ml}$ per minute per $\mathrm{m}^{2}(\mathrm{p}<0.01)$. The average body weight of the subjects decreased from a control level of 183 pounds at the end of the first week of the study to 178 pounds ( $p$ $<0.01$ ) during triiodothyronine. Serum cholesterol fell from an average control level of 202 $\mathrm{mg}$ per $100 \mathrm{ml}$ to $124 \mathrm{mg}$ per $100 \mathrm{ml}(\mathrm{p}<0.01)$ during the hypermetabolic period. Three weeks later, during the final control session, the average sleeping pulse rate, oxygen consumption, body weight, and serum cholesterol returned to, or nearly to, the initial control levels.

Each of the subjects developed various symptoms and signs of hypermetabolism. Most of them were aware of palpitation and pounding of the heart. Nervousness, tremor, and increased 


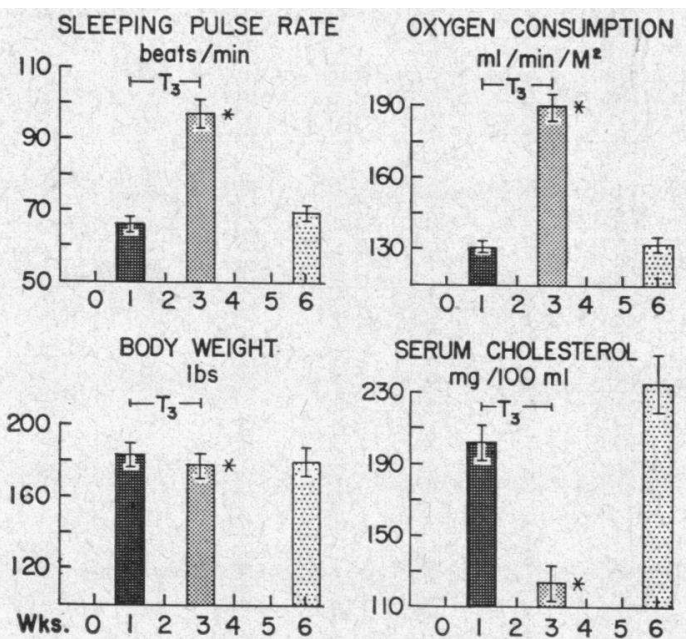

Fig. 1. EFFeCts of tritodothyronine (250 to $500 \mu \mathrm{G}$ PER DAY) FOR 14 DAYS IN EIGHT NORMAL SUBJECTS. The asterisks indicate values significantly different from the average of the pretreatment and the post-treatment control measurements. Each bar represents a mean value \pm standard error. $T_{3}=$ triiodothyronine.

irritability were prominent in the majority of subjects especially during the time they were receiving 400 to $500 \mu \mathrm{g}$ of triiodothyronine per day.

The infusions of isoproterenol, the inhalations of amyl nitrite, and the mild exercise were well tolerated by all of the subjects during each session. Some of them had palpitation and pounding of the heart during infusion of the largest dose of isoproterenol. These symptoms did not occur during any of the infusions of isoproterenol after intravenous propranolol. The clinical manifestations of drug-induced hypermetabolism were not affected by beta-adrenergic receptor blockade.

Analysis of the hematocrits from blood samples from the right atrium at the end of each hemodynamic study showed that there was a small reduction from an average control level of $40 \%$ in the first session to $37 \%(\mathrm{p}<0.05)$ during the hypermetabolic period. The average hematocrit of $38 \%$ obtained at the end of the final session was similar to that of the other two periods.

No adverse effects of propranolol were noted in these studies as measured by changes in leukocyte count, differential cell count, serum glutamic-oxaloacetic transaminase, blood urea nitrogen, and urinalysis.

Effects of isoproterenol before and after intravenous propranolol. The effects of isoproterenol on heart rate, cardiac index, and systemic mean arterial and mean right atrial pressures before and after propranolol ( $0.15 \mathrm{mg}$ per $\mathrm{kg}$ iv) in each of the three sessions are shown in Figure 2. Triiodothyronine produced an increase in control heart rate from 65 to 95 beats per minute ( $p$ $<0.01$ ) and in cardiac index from 3.0 to $4.3 \mathrm{~L}$ per minutes per $\mathrm{m}^{2}(\mathrm{p}<0.01)$ but did not change the control systemic arterial or mean right atrial pressures appreciably. Before propranolol, isoproterenol produced a significant dose-related increase in heart rate in each session. These doseresponse curves were linear and parallel. Analysis of variance (Table I) shows that the increments in heart rate during isoproterenol infusions in the hypermetabolic period were not significantly different from those found during isoproterenol administration in the two control periods. The increases in cardiac output during isoproterenol were slightly, but significantly, greater during the two control periods than during the hypermetabolic period. After propranolol, isoproterenol did not produce appreciable increases in heart rate or cardiac output in any session.

The initial systemic mean arterial pressures before propranolol averaged 93,90 , and $84 \mathrm{~mm}$ $\mathrm{Hg}$, respectively, in the three sessions. The average decreases in systemic mean arterial pressure during the two control sessions were similar and not significantly different from those observed with

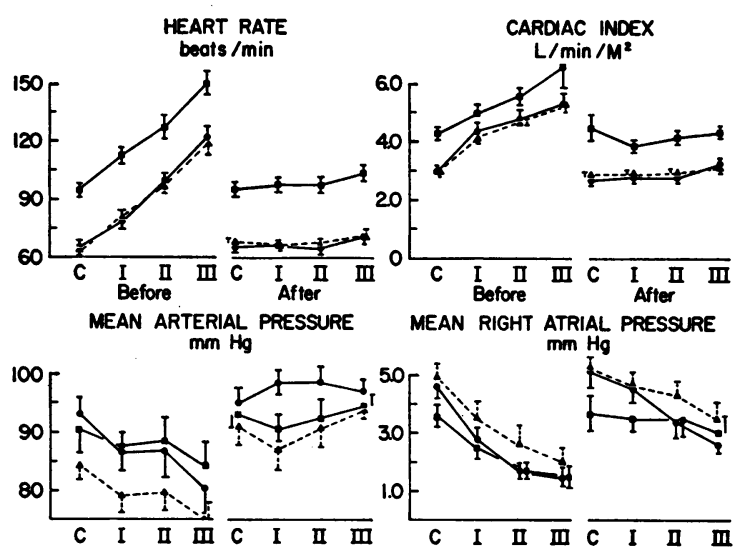

Fig. 2. EFFECTS OF ISOPROTERENOL BEFORE AND AFTER BETA-ADRENERGIC RECEPTOR BLOCKADE. The solid dots and triangles represent average values during the first and final control sessions ( $A$ and $C$ ); the squares indicate values during the hypermetabolic period (B). Mean values ( \pm standard error) are shown. $C$ refers to control measurements. I, II, and III refer to measurements made during infusions of graded doses of isoproterenol. 
TABLE I

Analysis of variance of changes in cardiac hemodynamics during isoproterenol infusions in the three sessions before propranolol*

\begin{tabular}{|c|c|c|c|c|c|c|c|c|c|}
\hline \multirow[b]{2}{*}{$\begin{array}{l}\text { Sources of } \\
\text { variation } \dagger\end{array}$} & \multirow[b]{2}{*}{$\mathrm{dF}$} & \multicolumn{2}{|c|}{ Heart rate } & \multicolumn{2}{|c|}{ Cardiac index } & \multicolumn{2}{|c|}{$\begin{array}{c}\text { Systemic mean } \\
\text { arterial pressure }\end{array}$} & \multicolumn{2}{|c|}{$\begin{array}{l}\text { Mean right atrial } \\
\text { pressure }\end{array}$} \\
\hline & & Mean square & $\mathrm{F} \ddagger$ & Mean square & $\mathrm{F}$ & Mean square & F & $\begin{array}{c}\text { Mean } \\
\text { square }\end{array}$ & F \\
\hline Sessions & 2 & 55.3 & 0.11 & 1.1 & 2.84 & 180.95 & 2.09 & 4.34 & $5.86 \S$ \\
\hline A vs. C & 1 & 63.0 & 0.13 & 0.003 & 0.01 & 58.5 & 0.68 & 2.02 & 2.73 \\
\hline$A+C$ vs. $B$ & 1 & 47.8 & 0.10 & 2.3 & $5.75 \|$ & 303.34 & 3.51 & 6.67 & $9.01 \S$ \\
\hline Regression & 1 & $20,377.5$ & $41.33 \S$ & 17.6 & $44.00 \S$ & 368.5 & $4.26 \|$ & 14.64 & $19.78 \S$ \\
\hline Nonparallelism & 2 & 60.4 & 0.12 & 0.4 & 1.00 & 1.65 & 0.19 & 0.07 & 0.09 \\
\hline Nonlinearity & 1 & 98.3 & 0.20 & 0.036 & 0.09 & 164.7 & 1.90 & 1.74 & 2.35 \\
\hline Error & 56 & 492.99 & & 0.4 & & 86.5 & & 0.74 & \\
\hline Total & 71 & & & & & & & & \\
\hline
\end{tabular}

* The three sessions were the initial hemodynamic study (A), the study after 2 weeks of oral administration of triiodothyronine (B), and the final control study, which was done 3 weeks after the triiodothyronine was stopped (C). The increases in heart rate and the decreases in systemic mean arterial pressure during isoproterenol infusions in the three sessions were linear and parallel but not significantly different from each other. The increments in cardiac output during isoproterenol were slightly but significantly greater during the two control periods than during the hypermetabolic period. The decrements in mean right atrial pressure were similar in the two control sessions (A and C); the decrements in mean right atrial pressure in the hypermetabolic session (B) were slightly but significantly less than in the controls $(A+C)$.

t Only the pertinent sources of variation are included.

$\ddagger$ F equals the variance ratio obtained by dividing the appropriate mean square by the "error" mean square.

$\$ \mathrm{p}<0.01$.

$\| \mathrm{p}<0.05 ;$ the absence of a symbol indicates $\mathrm{p}>0.05$.

isoproterenol in the hypermetabolic session (Table I). After propranolol, the average control systemic mean arterial pressures in the three sessions were not significantly different from the average control values before beta-adrenergic receptor blockade. The absolute levels of arterial pressure during infusions of isoproterenol were higher after propranolol in each of the two control sessions $(\mathrm{p}<0.01)$ and in the hypermetabolic period $(\mathrm{p}$ $<0.05$ ) than their respective levels during isoproterenol before beta-adrenergic blockade.

Mean right atrial pressures before propranolol averaged 4.6 and $4.5 \mathrm{~mm} \mathrm{Hg}$, respectively, in the two control sessions. The mean right atrial pressure was slightly lower $(p<0.05)$ during the hypermetabolic period, averaging $3.6 \mathrm{~mm} \mathrm{Hg}$. During isoproterenol infusions mean right atrial pressure decreased in each period; the reductions in pressure were less during the triiodothyronine session than in the control sessions $(p<0.01)$. After propranolol, mean right atrial pressure averaged $5.1 \mathrm{~mm} \mathrm{Hg}$ in the initial control session and was slightly higher $(p<0.01)$ than before betaadrenergic blockade. Propranolol did not alter the control venous pressures in the other two sessions. Propranolol attenuated the reductions in mean right atrial pressure during isoproterenol infusions in each of the three sessions $(p<0.01)$.

Since the control mean arterial pressure did not vary and flow increased, the initial average total systemic resistance was lower $(p<0.01)$ in the hypermetabolic session before and after propranolol than in the euthyroid periods. Isoproterenol produced significant decreases in resistance in all sessions before propranolol; the decrements in resistance during isoproterenol infusions were less in the hypermetabolic session $(p<0.01)$ than during the control periods. Propranolol significantly attenuated the reductions in resistance during administration of isoproterenol in each session; its effects were not appreciably different in any period.

Effects of amyl nitrite before and after propranolol (Table II). The average control systemic mean arterial pressure during the hypermetabolic session was not appreciably different from those of the control sessions. Before propranolol, the average reductions in mean arterial pressure during inhalation of amyl nitrite were 20,34 , and $25 \mathrm{~mm} \mathrm{Hg}$ in sessions $\mathrm{A}, \mathrm{B}$, and $\mathrm{C}$, respectively. The subjects in session $A$ received only three inhalations of amyl nitrite and had smaller re- 
BETA-ADRENERGIC BLOCKADE IN $\mathrm{T}_{3}$-INDUCED HYPERMETABOLISM

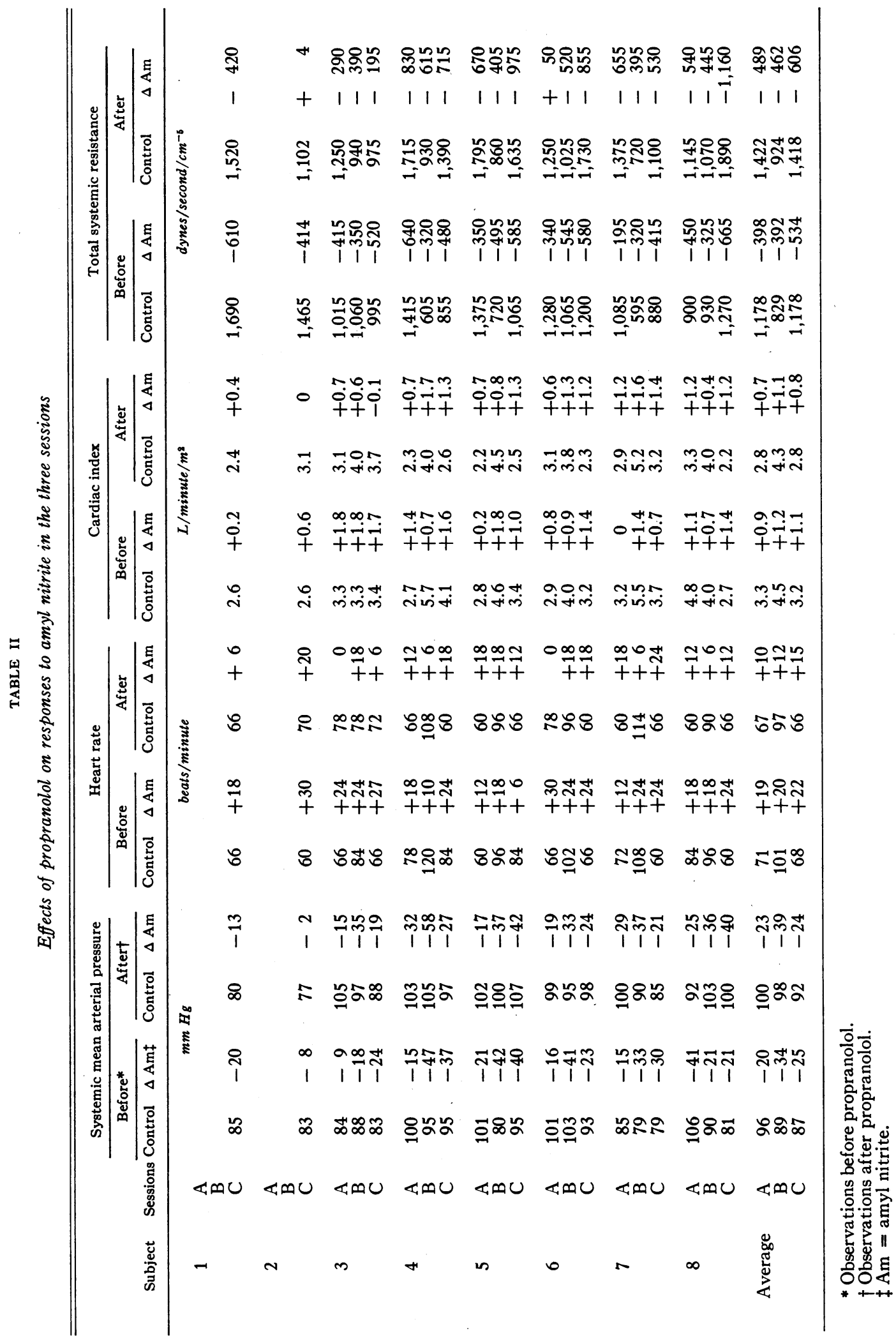


TABLE III

Hemodynamic effects of beta-adrenergic receptor blockade before

\begin{tabular}{|c|c|c|c|c|c|c|c|c|c|c|c|c|c|}
\hline \multirow[b]{3}{*}{ Subject } & \multirow[b]{3}{*}{ Sessions } & \multicolumn{4}{|c|}{$\mathrm{O}_{2}$ consumption } & \multicolumn{4}{|c|}{ Heart rate } & \multicolumn{4}{|c|}{ Mean right atrial pressure } \\
\hline & & \multicolumn{2}{|c|}{ Before* } & \multicolumn{2}{|c|}{ Aftert } & \multicolumn{2}{|c|}{ Before } & \multicolumn{2}{|c|}{ After } & \multicolumn{2}{|c|}{ Before } & \multicolumn{2}{|c|}{ After } \\
\hline & & Control & $\Delta \mathrm{Ex}$ & Control & $\Delta \mathrm{Ex}_{\mathbf{x}}$ & Control & $\Delta \mathrm{Ex}$ & Control & $\Delta \mathrm{Ex}$ & Control & $\Delta \mathrm{Ex}$ & Control & $\Delta \mathrm{Ex}$ \\
\hline & & & $m l / m$ & $u t e / m^{2}$ & & & beats & ninute & & & & $\mathrm{Hg}$ & \\
\hline \multirow[t]{3}{*}{1} & $\mathbf{A}$ & 144 & +104 & 144 & +294 & 60 & +18 & 72 & +12 & & & & \\
\hline & B & 219 & +271 & 235 & +346 & 96 & +24 & 90 & +30 & & & & \\
\hline & C & 135 & +205 & 136 & +222 & 66 & +24 & 66 & +18 & & & & \\
\hline \multirow[t]{3}{*}{2} & $\mathbf{A}$ & 130 & +171 & 130 & +170 & 72 & +12 & 54 & +12 & & & & \\
\hline & B & 164 & +206 & 196 & +159 & 84 & +24 & 84 & +24 & & & & \\
\hline & C & 125 & +193 & 122 & +217 & 60 & +24 & 70 & +20 & & & & \\
\hline \multirow[t]{3}{*}{3} & $\mathbf{A}$ & 158 & +190 & 172 & +129 & 72 & +18 & 72 & +12 & & & & \\
\hline & B & 218 & +128 & 190 & +117 & 90 & +18 & 84 & +18 & & & & \\
\hline & C & 133 & +156 & 124 & +140 & 72 & +24 & 66 & +22 & - & & & \\
\hline \multirow[t]{3}{*}{4} & A & 121 & +194 & 129 & +246 & 78 & +24 & 60 & +18 & 2.5 & +1.8 & 3.3 & +2.7 \\
\hline & B & 199 & +276 & 201 & +250 & 108 & +24 & 102 & +24 & 3.3 & +1.7 & 2.0 & -0.5 \\
\hline & $\mathrm{C}$ & 141 & +111 & 125 & +153 & 72 & +18 & 66 & +22 & 3.0 & +1.5 & 4.0 & +2.8 \\
\hline \multirow[t]{3}{*}{5} & A & 141 & +144 & 146 & +123 & 66 & +18 & 54 & +24 & 2.5 & +0.5 & 5.5 & +3.5 \\
\hline & B & 182 & +195 & 208 & +183 & 96 & +12 & 102 & +6 & 2.0 & +2.5 & 1.8 & +3.7 \\
\hline & C & 125 & +160 & 200 & +103 & 60 & +30 & 72 & +18 & 5.0 & -0.2 & 2.0 & +3.5 \\
\hline \multirow[t]{3}{*}{6} & $\mathbf{A}$ & 169 & +178 & 148 & +235 & 72 & +24 & 60 & +36 & 4.5 & -1.0 & 4.3 & +4.5 \\
\hline & B & 222 & +432 & 209 & +430 & 108 & +30 & 108 & +18 & 3.5 & +2.3 & 3.0 & +4.0 \\
\hline & C & 133 & +304 & 135 & +300 & 69 & +27 & 54 & +36 & 5.0 & +0.5 & 6.3 & +4.2 \\
\hline \multirow[t]{3}{*}{7} & A & 118 & +290 & 123 & +316 & 60 & +36 & 60 & +30 & 6.0 & -2.2 & 5.0 & +1.3 \\
\hline & B & 179 & +156 & 190 & +116 & 120 & +24 & 108 & +18 & 6.0 & 0 & 6.6 & +1.8 \\
\hline & C & 127 & +211 & 118 & +279 & 60 & +36 & 72 & +36 & 5.0 & -2.5 & 5.3 & +1.7 \\
\hline \multirow[t]{3}{*}{8} & $\mathbf{A}$ & 126 & +256 & 138 & +346 & 66 & +36 & 72 & +30 & 3.8 & -2.3 & 5.5 & +0.8 \\
\hline & B & 204 & +309 & 173 & +385 & 96 & +36 & 90 & +36 & 5.0 & -0.5 & 4.8 & +6.2 \\
\hline & C & 155 & +294 & 135 & +370 & 72 & +24 & 66 & +30 & 3.0 & +1.8 & 5.8 & +4.2 \\
\hline \multirow[t]{3}{*}{ Average } & $\mathbf{A}$ & 138 & +190 & 141 & +232 & 68 & +23 & 63 & +22 & 3.9 & -0.6 & 4.7 & $+2.6 \ddagger$ \\
\hline & B & 198 & +247 & 200 & +248 & 100 & +24 & 96 & +22 & 4.0 & +1.2 & 3.6 & +3.0 \\
\hline & C & 134 & +204 & 137 & +223 & 66 & +26 & 67 & +25 & 4.2 & +0.2 & 4.7 & $+3.1 \ddagger$ \\
\hline
\end{tabular}

* Observations made before and during the fifth minute of recumbent exercise (bicycle ergometer) before propranolol.

Observations made before and during the fifth minute of recumbent exercise (bicycle ergometer) after propranolol.
The average increments in mean right atrial pressure during exercise after propranolol in sessions $\mathrm{A}$ and $\mathrm{C}$ were greater than the changes in $\ddagger$ The average increments in mean right atrial pressure during exercise after propra
mean right atrial pressure during exercise before beta-adrenergic blockade $(p<0.02)$.

\& The increases in systemic mean arterial pressure during exercise were less after propranolol $(p<0.05)$ in the first session.

If The average decrement in resistance during exercise was greater after propranolol $(p<0.01)$ in the first session.

ductions in pressure. The changes in mean arterial pressure during amyl nitrite inhalation during the time the subjects were hypermetabolic, however, were not appreciably different from those of the final control session. Each subject inhaled amyl nitrite for six breaths during sessions $B$ and C. After propranolol, the average control systemic mean arterial pressures were similar in the three sessions and not significantly different from their respective control levels before beta-adrenergic blockade. The reductions in mean arterial pressure after amyl nitrite did not vary appreciably from those observed before propranolol.

The control heart rate in the hypermetabolic session averaged 101 beats per minute as compared with average rates of 71 and 68 beats per minute in the two control periods. Before propranolol, the average increase in heart rate during inhala- tion of amyl nitrite in the hypermetabolic session was 20 beats per minute; the average increases in heart rate in the two control sessions during amyl nitrite were 19 and 22 beats per minute. Propranolol attenuated the average increment in heart rate during amyl nitrite inhalation in the hypermetabolic session $(p<0.05)$ and during the final control session $(p<0.05)$. In the first control session, propranolol also reduced the average increment in heart rate from 19 beats to 10 beats per minute, but the changes were not of sufficient magnitude to achieve statistical significance as defined for this study (actual $\mathrm{p}$ value $<0.10$ ).

The control cardiac output during triiodothyronine administration before amyl nitrite averaged $4.5 \mathrm{~L}$ per minute per $\mathrm{m}^{2}$ compared with average control values in the two control sessions of 3.3 and $3.2 \mathrm{~L}$ per minute per $\mathrm{m}^{2}$, respectively. Be- 
TABLE III

and during exercise in eight normal subjects in the three sessions

\begin{tabular}{|c|c|c|c|c|c|c|c|c|c|c|c|}
\hline \multicolumn{4}{|c|}{ Systemic mean arterial pressure } & \multicolumn{4}{|c|}{ Cardiac index } & \multicolumn{4}{|c|}{ Total systemic resistance } \\
\hline \multicolumn{2}{|c|}{ Before } & \multicolumn{2}{|c|}{ After } & \multicolumn{2}{|c|}{ Before } & \multicolumn{2}{|c|}{ After } & \multicolumn{2}{|c|}{ Before } & \multicolumn{2}{|c|}{ After } \\
\hline Control & $\Delta \mathrm{Ex}$ & Control & $\Delta \mathrm{Ex}$ & Control & $\Delta \mathrm{Ex}$ & Control & $\Delta \mathrm{Ex}$ & Control & $\Delta \mathrm{Ex}_{\mathbf{x}}$ & Control & $\Delta \mathrm{Ex}$ \\
\hline \multicolumn{4}{|c|}{$m m \mathrm{Hg}$} & \multicolumn{4}{|c|}{$L /$ minute $/ m^{2}$} & \multicolumn{4}{|c|}{ dynes $/$ second $/ \mathrm{cm}^{-5}$} \\
\hline 96 & +18 & 101 & +11 & 2.9 & +0.9 & 2.4 & +1.3 & 1,490 & -160 & 1,895 & -540 \\
\hline 95 & +5 & 100 & +3 & 3.5 & +1.6 & 3.8 & +1.1 & 1,250 & -365 & 1,205 & -250 \\
\hline 85 & +1 & 81 & +9 & 2.6 & +1.3 & 2.7 & +1.1 & 1,530 & -510 & 1,365 & -295 \\
\hline 77 & +20 & 82 & +10 & 2.6 & +1.1 & 2.4 & +2.8 & 1,300 & -140 & 1,470 & -700 \\
\hline 83 & +12 & 92 & 0 & 3.7 & +1.6 & 4.4 & +0.8 & 1,015 & -210 & 940 & -145 \\
\hline 83 & +12 & 77 & +3 & 2.6 & +1.8 & 3.1 & +1.0 & 1,465 & -500 & 1,100 & -230 \\
\hline 90 & -3 & 101 & -4 & 3.5 & +1.0 & 2.9 & +0.8 & 1,040 & -260 & 1,425 & -365 \\
\hline 84 & +3 & 88 & -2 & 4.1 & +0.6 & 3.1 & +0.7 & 845 & -85 & 1,150 & -230 \\
\hline 73 & +10 & 75 & +1 & 3.7 & +1.4 & 3.1 & +1.0 & 815 & -150 & 990 & -225 \\
\hline 102 & +5 & 105 & -10 & 3.3 & +1.1 & 2.3 & +1.6 & 1,175 & -265 & 1,725 & -815 \\
\hline 95 & 0 & 85 & +10 & 4.7 & +2.1 & 4.4 & +0.9 & 775 & -245 & 725 & -45 \\
\hline 95 & -1 & 87 & +6 & 3.5 & +1.7 & 2.7 & +2.1 & 1,010 & -335 & 1,195 & -470 \\
\hline 100 & +13 & 101 & +6 & 2.7 & +1.2 & 2.2 & +1.0 & 1,400 & -295 & 1,745 & -485 \\
\hline 90 & +7 & 106 & -6 & 4.7 & +1.0 & 4.6 & -0.1 & 725 & -75 & 880 & -30 \\
\hline 76 & +19 & 102 & +5 & 2.9 & +1.5 & 2.8 & +0.8 & 1,015 & -185 & 1,380 & -225 \\
\hline 98 & +22 & 95 & +25 & 3.7 & +0.7 & 2.5 & +1.9 & 1,085 & +45 & 1,530 & -420 \\
\hline 106 & +17 & 95 & +22 & 3.9 & +3.2 & 3.9 & +3.7 & 1,125 & -415 & 1,015 & -385 \\
\hline 89 & +19 & 93 & +13 & 3.5 & +1.8 & 2.8 & +1.7 & 1,045 & -210 & 1,340 & -370 \\
\hline 88 & +20 & 95 & +14 & 3.1 & +2.4 & 2.9 & +1.9 & 1,170 & -370 & 1,355 & -440 \\
\hline 90 & -10 & 95 & +10 & 7.1 & +1.3 & 5.6 & +2.4 & 530 & -135 & 710 & -190 \\
\hline 30 & +15 & 97 & -7 & 3.2 & +2.3 & 3.0 & +2.4 & 1,025 & -315 & 1,330 & -640 \\
\hline 91 & +29 & 103 & +17 & 3.2 & +2.7 & 3.9 & +1.4 & 1,150 & -325 & 1,070 & -185 \\
\hline 100 & +14 & 100 & +5 & 3.9 & +3.1 & 3.0 & +3.1 & 1,060 & -390 & 1,365 & -620 \\
\hline 91 & +9 & 87 & +18 & 2.9 & +1.8 & 2.7 & +2.4 & 1,285 & -405 & 1,310 & -460 \\
\hline 93 & +16 & 98 & +98 & 3.1 & +1.4 & 2.7 & +1.6 & 1,226 & -221 & 1,527 & $-494 \|$ \\
\hline 93 & +6 & 95 & +5 & 4.5 & +1.8 & 4.1 & +1.6 & 916 & -240 & 999 & -237 \\
\hline 84 & +11 & 86 & +6 & 3.1 & +1.7 & 2.9 & +1.6 & 1,149 & -326 & 1,251 & -278 \\
\hline
\end{tabular}

fore propranolol, the average increase in cardiac output during the hypermetabolic period after amyl nitrite inhalation was $1.2 \mathrm{~L}$ per minute per $\mathrm{m}^{2}$, as compared with average increments of 0.9 and $1.1 \mathrm{~L}$ per minute per $\mathrm{m}^{2}$ in the two control periods. Propranolol did not appreciably alter the control values of cardiac output and also did not significantly attenuate the increments in cardiac output during inhalation of amyl nitrite in any session.

The average control calculated total systemic resistance before amyl nitrite was lower $(p<$ 0.01 ) during the hypermetabolic period than during the two euthyroid sessions both before and after propranolol. Beta-adrenergic receptor blockade did not alter the control levels of resistance in any session. The average decrements in total systemic resistance during inhalation of amyl ni- trite were not significantly different in the three sessions before or after beta-adrenergic receptor blockade.

Effects of exercise before and after intravenous propranolol. The effects of supine leg exercise on oxygen consumption, heart rate, cardiac index, and systemic mean arterial and mean right atrial pressures before and after beta-adrenergic receptor blockade in the three sessions are shown in Table III. Before propranolol, the average control oxygen consumption during the hypermetabolic session was higher than those of the control periods $(p<0.01)$. The average increments in oxygen consumption during exercise before propranolol, however, were not appreciably different in the three periods. Propranolol did not alter the control oxygen consumption in any of the three sessions. The average increases in oxygen consump- 
tion during exercise after propranolol were similar in the three periods.

The average control heart rate before propranolol was significantly higher in the hypermetabolic period than in the control sessions ( $p$ $<0.01)$. During exercise, however, the increments in heart rate before beta-adrenergic receptor blockade were not significantly different during the period of triiodothyronine administration as compared to those of the control sessions. Propranolol alone did not appreciably alter the control heart rates in any session, nor did it significantly attenuate the increments in heart rate during exercise in either the hypermetabolic or the control sessions.

The average control levels of mean right atrial pressure (in five of eight subjects in which it was measured) before exercise were similar in the three periods before and after propranolol. The increments in mean right atrial pressure during exercise were larger after propranolol in each session as compared with the changes in mean right atrial pressure during exercise before beta-adrenergic blockade, but statistically significant differences were only obtained in the two control sessions.

The average resting supine mean arterial pressure during the period of triiodothyronine administration was not appreciably different from the average mean arterial pressures during the control sessions. Exercise produced a small increase in systemic mean arterial pressure during the control sessions $(p<0.01)$, but not during the hypermetabolic period. Propranolol alone did not alter
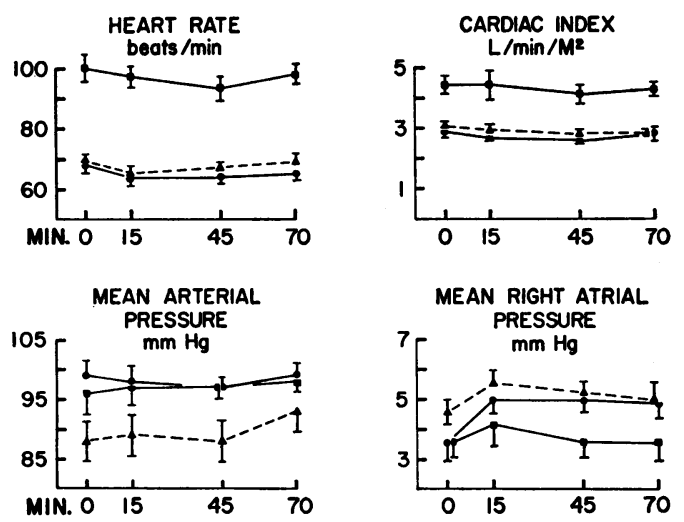

Fig. 3. EFFECTS OF PROPRANOLOL BEFORE, DURING, AND AFTER INDUCED HYPERMETABOLISM. Symbols for sessions $A, B$, and $C$ are identical to those of Figure 2. the average resting mean arterial pressure or the changes in pressure during exercise in the three sessions. The changes in mean arterial pressure during exercise after propranolol were not appreciably different from those occurring with exercise before the beta-adrenergic-blocking drug was given in either the hypermetabolic or the final control session.

The average resting cardiac index during the hypermetabolic session was higher than those of the control periods $(p<0.01)$. The average increases in cardiac index with supine leg exercise were similar during the three sessions before propranolol. The average resting cardiac indexes were not appreciably altered by the beta-adrenergic-blocking drug. The increments in cardiac index during exercise were similar in the three periods after propranolol and not appreciably different from the increases in flow during exercise before propranolol.

Since the resting levels of pressure were similar and the resting flows were higher in the hypermetabolic session than in the two control periods, the average systemic resistance at rest was lower in the hypermetabolic period $(p<0.01)$. The average reductions in calculated resistance during exercise were not significantly different in the three sessions. Propranolol did not change the resting total systemic resistance in either the hypermetabolic or the final control sessions; in the first control period the calculated total systemic resistance was slightly higher after the administration of propranolol. The average decrements in resistance during exercise after propranolol in the hypermetabolic and final control sessions were similar to the corresponding changes during exercise before propranolol. The average decrement in resistance during exercise in the first control session was significantly greater after propranolol as compared with the average change during exercise before the beta-adrenergic-blocking drug $(\mathrm{p}<0.01)$.

Effects of propranolol on heart rate, cardiac index, and mean arterial and mean right atrial pressures. The effects of propranolol $(0.15 \mathrm{mg}$ per $\mathrm{kg}$ ) on the average control levels of heart rate, cardiac index, and systemic mean arterial and mean right atrial pressures at 15,45 , and 70 minutes after its infusion into the right atrium are shown in Figure 3. The average control values 
depicted for each session were those recorded just before propranolol was given via the right atrial catheter. The average control heart rate and average cardiac index were appreciably higher in the hypermetabolic session than during the control sessions. The average heart rate and cardiac index at 15, 45, and 70 minutes after propranolol in each session, however, were not appreciably different from their respective control values. The absolute levels of systemic mean arterial pressure in each session at the same time intervals after propranolol were also not significantly different from their respective control levels. Calculated average total systemic resistances at the 15-, 45-, and 70-minute periods were not appreciably different from their control values before propranolol. The average mean right atrial pressures in both control sessions were slightly, but significantly, higher only at the 15 -minute period after propranolol. In the hypermetabolic session the average mean right atrial pressure was not appreciably different from control at 15, 45, and 70 minutes after propranolol.

\section{Discussion}

These results show clearly that in the dose used in these studies $(0.15 \mathrm{mg}$ per $\mathrm{kg}$ ) propranolol can produce effective beta-adrenergic receptor blockade. The effects of graded doses of isoproterenol on heart rate, cardiac output, and mean arterial and mean right atrial pressures of normal subjects were blocked or significantly attenuated by propranolol in the hypermetabolic session as well as in the two control periods. We cannot necessarily infer from these results, nor from similar results in a previous study in patients with spontaneous hyperthyroidism (1), that beta-adrenergic stimulation by endogenous catecholamines was blocked. Therefore, the hemodynamic responses to amyl nitrite were studied in each session as an indirect means of testing the ability of propranolol to block reflex stimulation of beta-adrenergic receptors. Significant attenuation of the average increments in heart rate during amyl nitrite inhalation in the hypermetabolic and final control sessions provides additional evidence that effective beta-adrenergic receptor blockade was achieved in these subjects in the hypermetabolic and control sessions.
The present study also clearly shows that in normal subjects triiodothyronine did not augment the hemodynamic responses to graded doses of isoproterenol. The increments in heart rate and the decrements in mean arterial and mean right atrial pressures with isoproterenol during the hypermetabolic session were not significantly different from those of the control sessions when the subjects were euthyroid. Moreover, the increases in cardiac output during infusions of isoproterenol were slightly but significantly less when the subjects were hypermetabolic than when they were euthyroid. Thus, the chief difference between the subject with triiodothyronine-induced hypermetabolism and the normal subject is the starting level of heart rate and cardiac output, rather than the changes in response to isoproterenol. A similar study of the effects of triiodothyronine on the hemodynamic responses to graded doses of the naturally occurring catecholamine, epinephrine, has recently been reported from our laboratories (8). The increments in heart rate, cardiac output, and mean arterial and mean right atrial pressure with graded doses of epinephrine during a period of triiodothyronine-induced hypermetabolism were similar to those of the euthyroid period in eight normal subjects.

These studies in man, coupled with those of Van der Schoot and Moran (9) and Margolius and Gaffney (10) in animals, indicate that the hemodynamic changes in hyperthyroidism are not mediated through stimulation of beta-adrenergic receptors and refute the old concept that excess thyroid hormone augments the actions of catecholamines.

The effects of beta-adrenergic receptor-blocking drugs on the hemodynamic responses of normal subjects and of patients with heart disease to various grades of exercise have been reported by several groups (11-15). Epstein, Robinson, Kahler, and Braunwald have clearly shown that although propranolol reduces the circulatory responses to maximal and submaximal exercise in normal subjects and in patients with cardiac disorders, cardiac output still rises considerably during exercise after beta-adrenergic receptor blockade (15). No attempt was made in the present study to achieve maximal levels of exercise. The increments in oxygen consumption during exercise were modest in comparison with those reported by 
Epstein and co-workers (15). The lack of effect of the identical intravenous dosage of propranolol on the hemodynamic responses to mild exercise in these normal subjects during either the hypermetabolic or the control sessions leads us to agree that sympathetic stimulation of the heart plays a minor role in the responses to mild exercise in the normal subject or in the hypermetabolic subject. A number of other mechanisms may be involved when beta-adrenergic receptors are blocked during exercise. Withdrawal of vagal tone may partially explain increased heart rate during exercise after propranolol. During exercise the average increments in mean right atrial pressure were greater after propranolol than those during exercise before the beta-adrenergic receptor-blocking drug. Thus, an increase in venous return could still occur secondary to systemic venoconstriction and the pumping action of the skeletal muscles. Beta-adrenergic receptor blockade did not reduce the decrease in total peripheral resistance during exercise in any session. This finding suggests that vasodilation might occur through mechanisms independent of beta-adrenergic receptors. It is known that the increase in cutaneous blood flow of the forearm in thyrotoxicosis is largely mediated by a cholinergic mechanism (16).

\section{Summary}

The effect of beta-adrenergic receptor blockade was studied in eight normal subjects before, during, and after a period of triiodothyronine-induced hypermetabolism. Hemodynamic responses were measured during infusions of graded doses of isoproterenol, during inhalation of amyl nitrite, and after mild exercise before and after propranolol.

Propranolol inhibited the chronotropic and inotropic effects of isoproterenol but did not significantly change oxygen consumption, heart rate, systemic mean arterial pressure, cardiac output, or total systemic resistance in these subjects in either the hypermetabolic or the two control sessions.

Beta-adrenergic receptor blockade did not alter the fall in mean arterial pressure during inhalation of amyl nitrite in any session. Propranolol significantly attenuated the increase in heart rate, but not the rise in cardiac output during amyl nitrite in the hypermetabolic and final control sessions.

The hemodynamic responses to mild exercise were similar before and after propranolol in each period.

Triiodothyronine did not augment the hemodynamic responses to isoproterenol. The positive chronotropic and the vasodepressor effects of isoproterenol were similar in the three sessions. The increments in cardiac output during infusions of isoproterenol were slightly but significantly greater in the control sessions than those of the hypermetabolic session.

These studies in man indicate that the hemodynamic changes in triidothyronine-induced hypermetabolism, like those of spontaneous hyperthyroidism, are not mediated through stimulation of beta-adrenergic receptors.

\section{Acknowledgments}

We obtained generous supplies of propranolol from Dr. Alex Sahagian-Edwards, Ayerst Laboratories, New York, N. Y.

\section{References}

1. Wilson, W. R., E. O. Theilen, and F. W. Fletcher. Pharmacodynamic effects of beta-adrenergic receptor blockade in patients with hyperthyroidism. J. clin. Invest. 1964, 40, 1697.

2. Brewster, W. R., Jr., J. P. Isaacs, P. A. Osgood, and T. L. King. The hemodynamic and metabolic interrelationships in the activity of epinephrine, norepinephrine and the thyroid hormones. Circulation 1956, 13, 1.

3. Black, J. W., A. F. Crowther, R. G. Shanks, L. H. Smith, and A. C. Dornhorst. A new adrenergic beta-receptor antagonist. Lancet 1964, 1, 1080.

4. Dixon, W. D., and F. J. Massey, Jr. Introduction to Statistical Methods, 2nd ed. New York, McGraw-Hill, 1957.

5. Finney, D. J. Statistical Method in Biological Assay. London, Griffin \& Co., 1952.

6. Dunnett, C. W. A multiple comparison procedure for comparing several treatments with a control. Amer. Statist. Ass. J. 1955, 50, 1096.

7. Dunnett, C. W. New tables for multiple comparisons with a control. Biometrics 1964, 20, 482.

8. Aoki, V. S., W. R. Wilson, E. O. Theilen, W. W. Lukensmeyer, and P. E. Leaverton. Effects of triiodothyronine $\left(T_{3}\right)$ on the hemodynamic responses to epinephrine in normal subjects (abstract). Clin. Res. 1965, 13, 398.

9. Van der Schoot, J. B., and N. C. Moran. An experimental evaluation of the reputed influence of thy- 
roxine on the cardiovascular effects of catecholamines. J. Pharmacol. exp. Ther. 1965, 149, 336.

10. Margolius, H. S., and T. E. Gaffney. The effects of injected norepinephrine and sympathetic nerve stimulation in hypothyroid and hyperthyroid dogs. J. Pharmacol. exp. Ther. 1965, 149, 329.

11. Harrison, D. C., E. Braunwald, G. Glick, D. Mason, C. A. Chidsey, and J. Ross, Jr. Effects of beta adrenergic blockade on the circulation, with particular reference to observations in patients with hypertrophic subaortic stenosis. Circulation 1964, 29, 84.

12. Bishop, J. M., and N. Segel. The circulatory effects of intravenous pronethalol in man at rest and during exercise in the supine and upright positions (abstract). J. Physiol. (Lond.) 1963, 169, 112 P.
13. Schröeder, G., and L. Werkö. Hemodynamic and clinical experience with nethalide, a beta-adrenergic blocking agent. Amer. J. Cardiol. 1965, 15, 58.

14. Chamberlain, D. A., and J. Howard. The hemodynamic effects of $\beta$-sympathetic blockade. Brit. Heart J. 1964, 26, 213.

15. Epstein, S. E., B. F. Robinson, R. L. Kahler, and E. Braunwald. Effects of beta-adrenergic blockade on the cardiac response to maximal and submaximal exercise in man. J. clin. Invest. 1965, 44, 1745.

16. Kontos, H. A., W. Shapiro, H. P. Mauck, Jr., D. W. Richardson, J. L. Patterson, Jr., and A. R. Sharpe, Jr. Mechanism of certain abnormalities of the circulation to the limbs in thyrotoxicosis. J. clin. Invest. 1965, 44, 947. 